\title{
Pigeon Louse Fly or Pigeon Fly ${ }^{1}$
}

William H. Kern, Jr. ${ }^{2}$

\section{Introduction}

The pigeon louse fly, Pseudolychia canariensis (Macquart) (Insecta: Diptera: Hippoboscidae)

(Figure 1) is a common, obligate blood-feeding, ectoparasite of pigeons and doves. Both adult males and females feed on the blood of their host. They are adapted for clinging to, and moving through, the plumage of their hosts. Strongly specialized claws help them cling to the feathers of their particular host species. Pigeon flies retain their wings for their entire adult life.

\section{Distribution}

This fly is an obligate parasite of birds, especially feral and domestic pigeons and doves (Columbiformes). It is found wherever pigeons are encountered in tropical, subtropical, and temperate areas with mild winters worldwide (Theodor,1975). It occurs throughout Florida and the southeastern United States.

\section{Identification}

Pigeon louse flies are brown dorso-ventrally flattened flies (Figure 2) that live among the body feathers of pigeons and doves. They are about the same size as house flies (5-6 $\mathrm{mm}$ head and body, wings 6-7 $\mathrm{mm}$ ) and are very slow fliers. They have a tough exoskeleton that protects them from being crushed by the grooming host.

\section{Life Histories and Habitat}

Louse flies have a very interesting reproductive strategy. The female produces one larva at a time and retains the developing larva in her body until it is ready to pupate. The larva feeds on the secretions of a "milk gland" in the uterus of its mother. Once the larva has reached its maximum size, the mother gives birth to the white pre-pupa which immediately begins to darken and form the puparium or pupal shell. The pupa of the pigeon louse fly looks like a dark brown, egg-shaped seed. (Figure 3) The pupa is found in the nest of the host or on ledges where the birds roost. When the fly has completed its metamorphosis, the winged adult emerges from the puparium and flies in search of a host.

\section{Hosts}

This fly is an obligate parasite of birds, especially feral and domestic pigeons (Columba livia) and doves (Columbiformes). Both sexes feed on the blood of the host bird. Pigeon flies very rarely bite

1. This document is ENY-687, one of a series of the Entomology and Nematology Department, Florida Cooperative Extension Service, Institute of Food and Agricultural Sciences, University of Florida. First printed September 2003. Please visit the EDIS Website at http://edis.ifas.ufl.edu.

2. William H. Kern, Jr., Assistant Professor, Entomology and Nematology, Ft. Lauderdale Research and Education Center, University of Florida, Davie, FL 33314 .

The Institute of Food and Agricultural Sciences is an equal opportunity/affirmative action employer authorized to provide research, educational information and other services only to individuals and institutions that function without regard to race, color, sex, age, handicap, or national origin. For information on obtaining other extension publications, contact your county Cooperative Extension Service office. Florida Cooperative Extension Service/Institute of Food and Agricultural Sciences/University of Florida/Christine Taylor Waddill, Dean. 


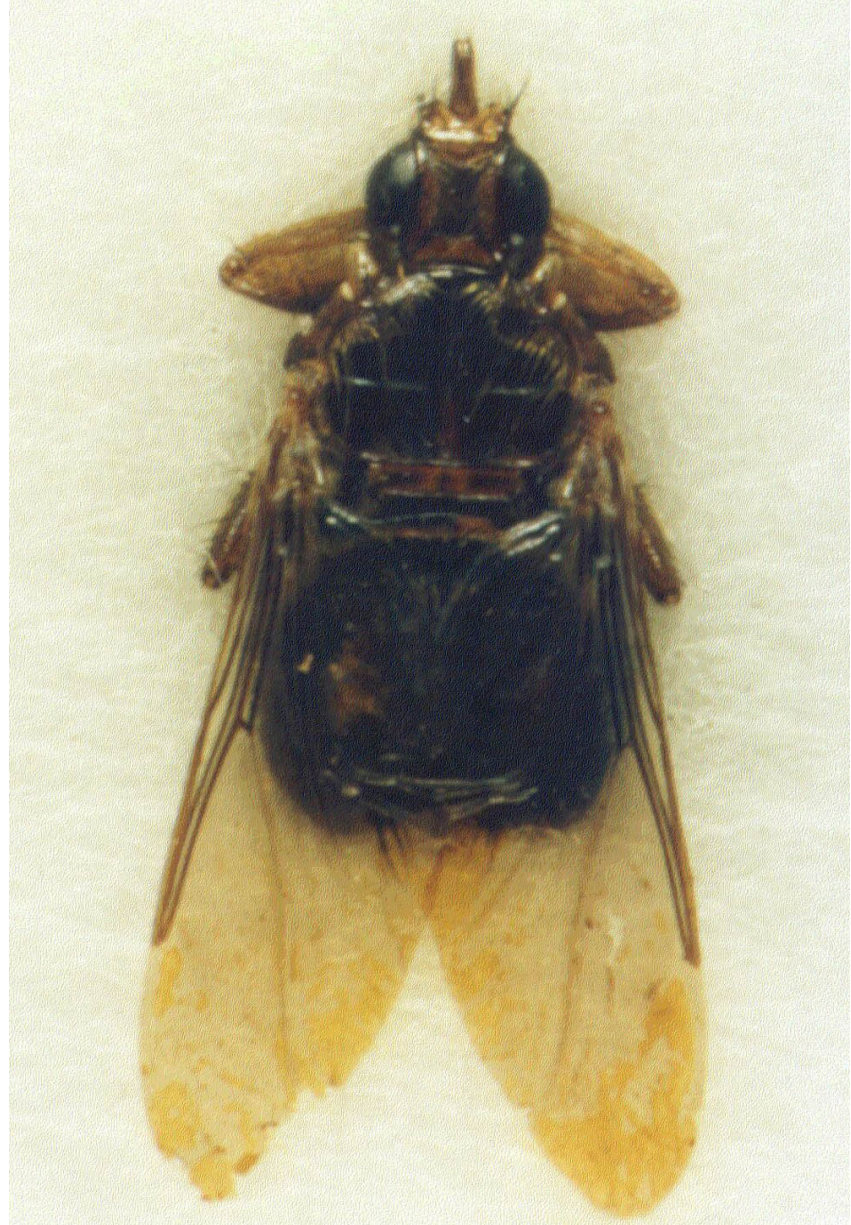

Figure 1. Dorsal view of female Pigeon fly. Credits: Karen Wheeler / UF-Ft. Lauderdale R.E.C.

humans. Usually this occurs when a person is handling live pigeons and the flies abandon the birds and land on the person. Occasionally, pigeon flies bite people after pigeons have been excluded from a structure. Newly emerged adults that are unable to find a bird host may go to humans in desperation and bite. Pigeon flies cannot survive on humans, however.

\section{Veterinary and Medical Importance}

The pigeon fly is the vector and intermediate host for the protozoan parasite of pigeons, Haemoproteus columbae (Haemoproteidae: Haemosporidia) (Soulsby, 1968). This malaria-like parasite has minimal effects on adult pigeons, but can be fatal to young birds. This disease does not infect humans or other mammals.

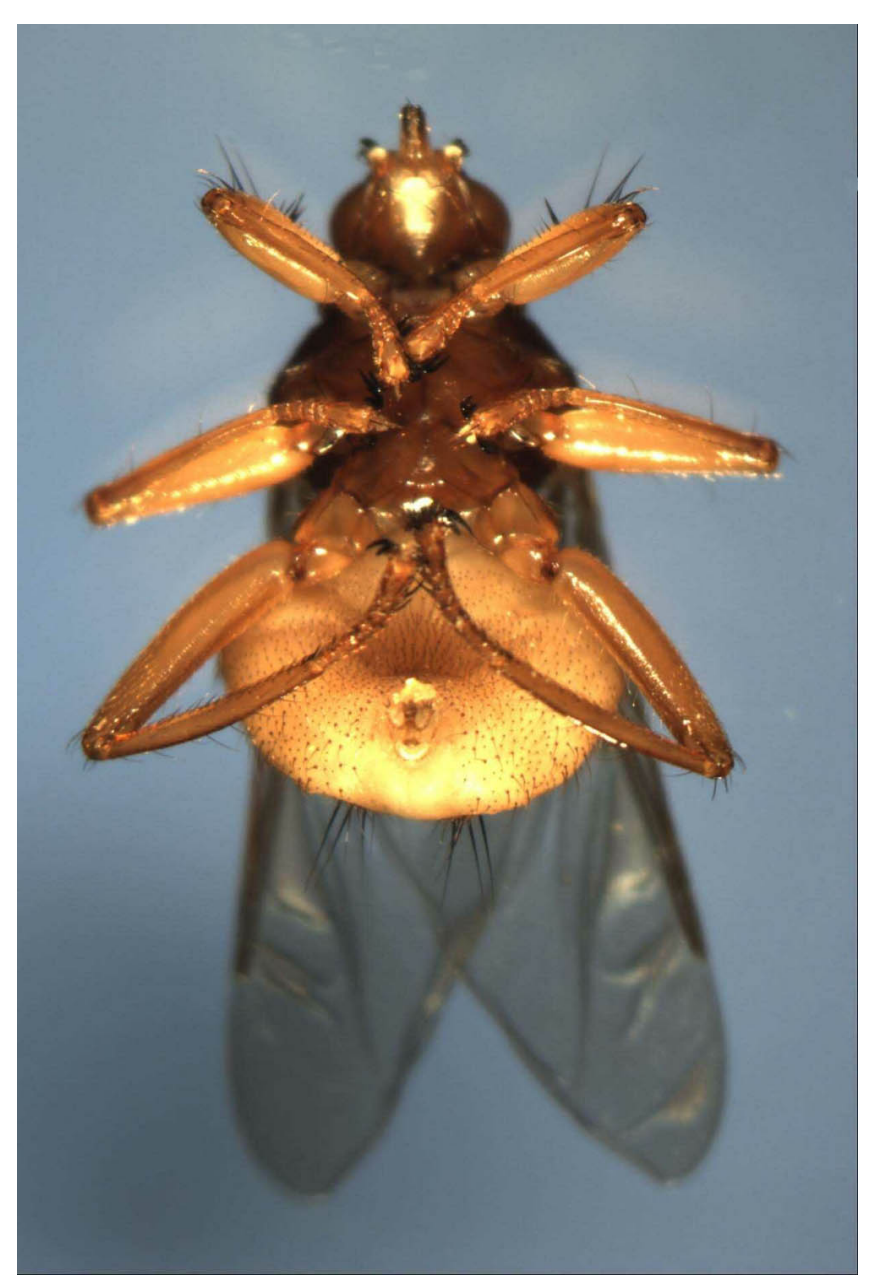

Figure 2. Ventral view of female Pigeon fly. Credits: Karen Wheeler / UF-Ft. Lauderdale R.E.C.

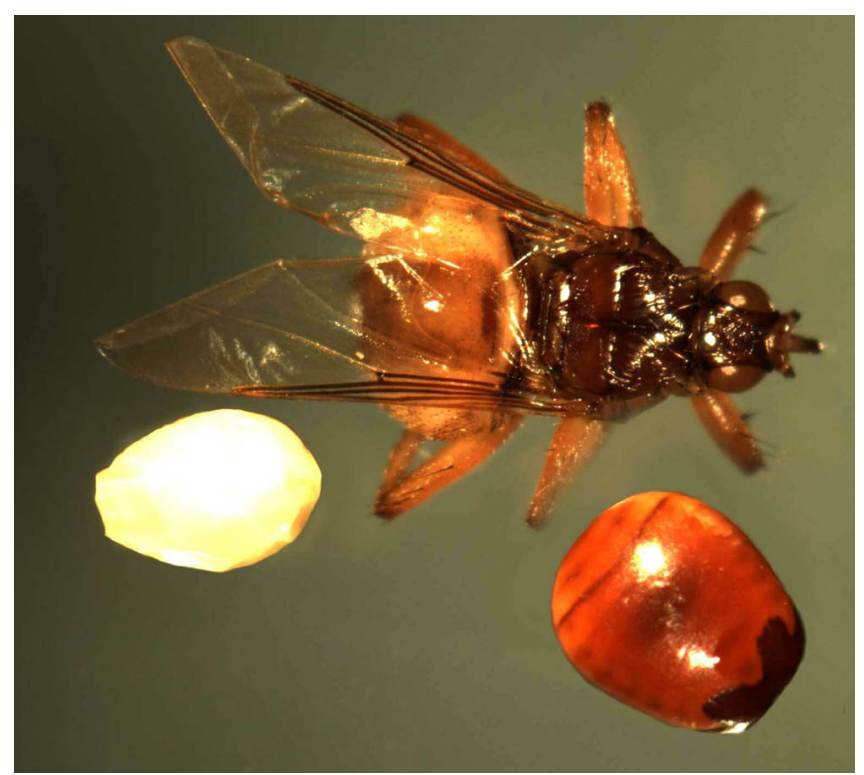

Figure 3. Pigeon fly life cycle; adult female (top center), white pre-pupa (bottom left), and brown pupa (bottom right). Credits: Karen Wheeler / UF-Ft. Lauderdale R.E.C. 
Pigeon lice in the suborder Ischnocera

(Phthiraptera [Mallophaga]) are sometimes found riding on pigeon flies. This is a phoretic (transportation) association and the lice do not feed on the flies. The lice clasp the legs or seta of the flys body and hitch a ride to the next bird visited by the pigeon fly.

\section{Control}

Pigeon flies are rarely a problem in well-maintained domestic pigeon coops. Domestic flocks can only become infested by co-mingling with feral birds. Treatment of domestic flocks with permethrin for lice and mites, probably controls pigeon flies as well. Preventing feral pigeons from roosting on or in buildings prevents occasional pigeon fly and bird mite nuisance situations for humans. If pigeon flies have become a problem because feral pigeons have been excluded, treatment of old roosting surfaces with permethrin or other registered pyrethroid should control temporary problem situations.

\section{Selected References}

Soulsby, E.J.L. 1968. Helminths, Arthropods, and Protozoa of Domesticated Animals. Williams and Wilkins Co., Baltimore, MD. p.692

Theodor, O. 1975. Diptera pupipara; Fauna Palaestina-Insecta I. The Israel Academy of Sciences and Humanities, Jerusalem, Israel. 170 pp. 